\title{
GAINT INGUINOSCROTAL HERNIA - LICHTENSTEIN'S TENSION FREE REPAIR WITHOUT LOSS OF DOMAIN: CASE REPORT
}

Sreekant Avula ${ }^{1}$, Shrivathsa Merta르, Samir Kumar Patel ${ }^{3}$

\section{HOW TO CITE THIS ARTICLE:}

Sreekant Avula, Shrivathsa Merta, Samir Kumar Patel. "Gaint Inguinoscrotal Hernia - Lichtenstein's Tension Free Repair without Loss of Domain: Case Report". Journal of Evolution of Medical and dental Sciences 2015; Vol. 4, Issue 22, March 16; Page: 3903-3906, DOI:10.14260/jemds/2015/561

ABSTRACT: Inguinal hernia is one of the most surgical common diseases in clinical practice. The history of inguinal hernia repair originated in the ancient times and the treatment has evolved, developed and changed since.[1] The most recent one is the concept of tension-free repair which remains popular among surgeons today. It is interesting to note, though, that numerous literatures have been published on this disease in the small anatomical space despite its simplicity. In the past couple of years, most publications focused on laparoscopic surgery and the different types of prosthetic mesh. Giant inguinal hernia, however, is more unusual and significantly challenging in terms of surgical management. It is defined as an inguinal hernia that extends below the midpoint of inner thigh when the patient is in standing position. ${ }^{[2]}$ No treatment has been adopted as standard procedure for this uncommon disease and several repair techniques are suggested by published articles and case reports. Further, the absence of large scale comparative study is expected to continue due to the relatively low number of cases. As a result, choosing a surgical procedure is made difficult and the decision must be made intraoperatively. A 55-year-old male patient presented with Left Giant inguinal hernia and compromised quality of life due to pain and sexual discomfort. Lichtenstein's polypropylene mesh repair was done after reducing the sac contents (omentum and ileum) with partial omentectomy. There was no loss of intra-abdominal domain. Postoperative period was uneventful. In literature many techniques are available to increase the intra-abdominal cavity (a) Creating progressive preoperative pneumoperitoneum (b) Creation of ventral wall defect (c) surgical debulking of hernia contents. Recurrence is prevented by reconstruction of the abdominal wall using Marlex mesh and a Tensor fasciae lata flap. Laparoscopic repair is associated with more recurrence. Lichtenstein's technique is one of the preferred treatments.

KEYWORDS: Abdominal compartment syndrome, Giant, Liechtenstein, Polypropylene mesh, Tension free repair, inguinoscrotal swelling, Hernia.

CASE PRESENTATION: A 55-year-old male patient came with complaint of Left Inguinoscrotal swelling since 25 yrs, insidious onset, gradually progressive and recently reached below level of midthigh, associated with dragging type of pain [Figure 1 Gaint Left Inguinoscrotal Hernia]. Patient's quality of life has been compromised because of interference with sexual activity and dribbling of urine to the scrotum. Patient was not able to perform his daily routine activities due to constant weight bearing and pain in his scrotum. History of Chronic Cough present. Patient is a known case of COPD.

On examination Pulse 78/min, BP 130/80 mm Hg, an oval shaped swelling 40x18x10 cms in Left Inguinoscrotal region, extending from left inguinal region up to left mid-thigh [Figure 1], surface smooth, borders well made out, only partially reducible, doughy in consistency, no cough impulse, non-tender, no local raise in temperature, not able to get above the swelling, scrotal skin was 
thickened and penis is buried in scrotum. Chest X-ray normal, USG abdomen-Left indirect inguinal hernia with enterocele and omentocele as its contents with good vascularity.

Patient posted for elective hernia repair and bladder catheterized after anaesthesia before incision. Hernia approached with Left Inguinal incision, indirect hernial sac noticed and sac was carefully dissected separating it from cord structures. The sac opened and contents found to be omentum and ileum [Figure 2 Intraoperative findings: the huge hernia sac $(\mathrm{H})$ was separated from right testis (T) (A). Terminal ileum, cecum, ascending colon and omentum were found as the contents of the hernia sac (B)]. Adhesions were lysed to make ileum free from omentum and hernial sac without any bowel resection. Partial omentectomy was done. The ileum and remaining omentum were successfully reduced back to abdominal cavity through wide deep ring without any change in intraoperative airway pressures.

Direct hernia component also noted through Hasselbach's triangle. Direct hernial contents were reduced. A $6 \mathrm{~cm} \times 11 \mathrm{~cm}$ polypropylene monofilament mesh was placed over the posterior wall of inguinal canal and fixed to it [Figure 3 lichensteins tension free only mesh repair]. Drain was placed in the scrotum and wound closed in layers. Post operatively after 24 hours drain was $30 \mathrm{ml}$ (bloody) without cardio respiratory distress. Post-operative day 2 and 3 drain decreased to $15 \mathrm{ml}$ and $5 \mathrm{ml}$ (serosangous) respectively. Drain was removed and patient discharged on postoperative day 4 . Patient was followed up weekly for the first month and every15 days from $2^{\text {nd }}$ month. Scrotal edema was there for two weeks, which gradually reduced.

DISCUSSION: Giant inguinal hernia is a chronic condition and rare in recent practice. It is defined as inguinal hernia extending till mid-thigh or below in the standing position. ${ }^{[2]}$ Penis is usually buried inside the scrotum causing dribbling of urine over an already edematous scrotal skin (lymphatic and venous oedema) leading to excoriation, ulceration and secondary infection. It is a challenge for the operating surgeon. Reducing large amount of abdominal viscera of giant hernial content to abdomen cavity may cause abdominal compartment syndrome which push the diaphragm towards thoracic cavity resulting in respiratory difficulty and compromised venous return leading to circulatory collapse.[3] Replacement of intestine into the abdominal cavity can also cause intestinal obstruction and wound dehiscence postoperatively.

There are few surgical techniques described in the literature for repairing giant Inguinoscrotal hernias. Most common one is creation of progressive preoperative pneumoperitoneum for two weeks by insufflating air into abdominal cavity. ${ }^{[4]}$ Another technique describes de-bulking the contents of the hernia sac by performing resection of the bowel in the hernia sac, and reconstruction of the abdominal wall using Marlex mesh and a tensor fasciae lata flap to prevent recurrence.[5] In 2001, El-Dessouki described a new way to achieve this by creating a midline abdominal wall defect to increase the intra-abdominal capacity to accommodate the hernia contents. The hernia sac is then pulled up to the abdomen and fashioned as a rotation flap to augment and close the peritoneum over the replaced contents.[6] Merret et al., described another similar technique which includes reduction of sac, hernial orifice repair with merlex mesh and creation of a midline abdominal wall defect followed by marlex Mesh with rotation flap of inguinoscrotal skin covering the defect.[7] Lastly, a giant polypropylene mesh is inserted in the preperitoneal space to cover the midline defect created and to buttress both inguinal regions. ${ }^{[8]}$ Laparoscopic repair of giant hernia can also be done but recurrence rate is high. Current guidelines suggest Lichtenstein repair as preferred surgical technique for large irreducible inguinal hernia.[9] 
CONCLUSION: Giant inguinal hernia is a formidable and challenging surgical disease associated with compromised quality of life. Surgical repair for the giant inguinal hernia is challenging and correlated with significant morbidity and mortalitydue to increased intra-abdominal pressure. Surgical techniques, in addition to forced reduction with simple hernioplasty, are resection of contents and intraabdominal volume increase procedure, combined with repair of hernia. The majority of publications on the subject are case reports and small case series, making it difficult to compare between the procedures. Application of appropriate technique for the individual patients is the key to success treatment and that is more important than strict adherence to any one technique. We treated it by simple Lichtenstein's mesh repair without loss of intra-abdominal domain. Postoperative period was uneventful.

\section{REFERENCES:}

1. Lau W. Y. History of treatment of groin hernia. World J Surg. 2002; 26(6): 748-759. [PubMed].

2. Hodgkinson D. J., Mcllrath D. C. Scrotal reconstruction for giant inguinal hernias. SurgClin North Am. 1980; 64: 307-313. [PubMed].

3. JW Serpell, AL Polglase, Anstee EJ. Giant inguinal hernia. ANZ Journal of surgery. 1988; 58: 83134.

4. Piskinv T, Aydin C, Barut B, Dirican A, Kayaalp C. Preoperative progressive pneumoperitonium for giant inguinal hernia. A Saudi Medicine. 2010, 30; 317-20.

5. Mehendal FV, Taams KO, Kingsnorth AN. Repair of a giant inguinoscrotal hernia. Br J Plast Surg. 2000; 53: 525-29.

6. El-Dessouki NI. Preperitoneal mesh hernioplasty in giant inguinoscrotal hernia: a new technique with dual benefit in repair and abdominal rooming. Hernia. 2001; 5: 177-81.

7. Merrett ND, Waterworth MW, Green MF. Repair of giant inguinoscrotal hernia using marlex mesh and scrotal skin flaps. Aust N Z J Surg. 1994; 64: 380-83.

8. Bernhardt GA, Gruber K, Gruber G. TAPP repair in giant bilateral scrotal hernia-limits of a method. AZN J Surg. 2010; 80: 947-48.

9. Simsons MP, Aufenacker T, Bay-Nielsen M, et al. European Hernia Society guidelines on the treatment of inguinal hernia in adult patients. 2009; 13: 343- 403.

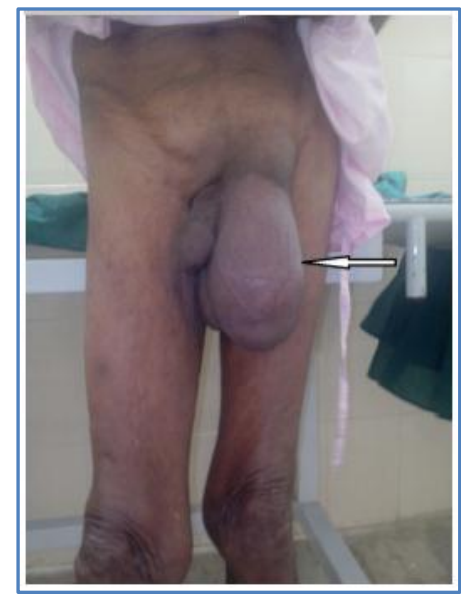

Figure 1: Gaint Left Inguinoscrotal Hernia 


\section{CASE REPORT}

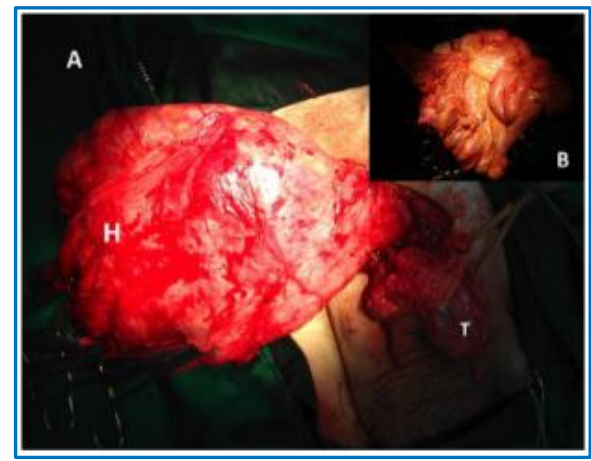

Fig. 2: Intraoperative findings: the huge hernia sac $(H)$ was separated from right testis (T) (A). Terminal ileum, cecum, ascending colon and omentum were found as the contents of the hernia sac (B).

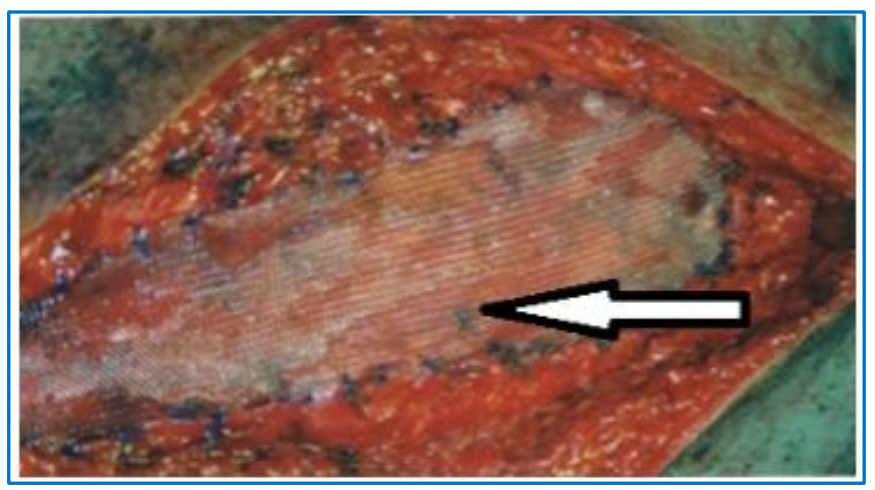

Fig. 3: LICHENSTEINS TENSION FREE ONLAY MESH REPAIR

\section{AUTHORS:}

1. Sreekant Avula

2. Shrivathsa Merta

3. Samir Kumar Patel

\section{PARTICULARS OF CONTRIBUTORS:}

1. Senior Resident, Department of Surgery, DMWIMS, Wayanad.

2. Senior Resident, Department of Surgery, MMCRI, Mysore.

3. Senior Resident, Department of Surgery, LG Hospital Ahmedabad, Gujarat.

FINANCIAL OR OTHER COMPETING INTERESTS: None

\section{NAME ADDRESS EMAIL ID OF THE} CORRESPONDING AUTHOR:

Dr. Sreekant Avula,

11/269, Upstairs, Gourav Homes,

Rudrampet,

Ananthapur-515004,

Andhra Pradesh.

E-mail: drsreekanth.ms@gmail.com

Date of Submission: 21/02/2015.

Date of Peer Review: 23/02/2015.

Date of Acceptance: 04/03/2015.

Date of Publishing: 16/03/2015. 